INDO GLOBAL JOURNAL OF

PHARMACEUTICAL SCIENCES

ISSN 2249- 1023

\title{
Bioenergy from Plants and Microbes
}

\author{
Saloni Sachdeva, Prakhar Agarwal, Sakshi Awasthi, Krishna K Sundari * \\ Department of Biotechnology, Jaypee Institute of Information Technology, Sector-62, Noida-201309, Uttar Pradesh, India \\ Address for Correspondance: Krishna K Sundari, krishna.sundari@jiit.ac.in ; salonisachdeva02@gmail.com ; aprakhar50@gmail.com ; \\ sakshi2008awasthi@gmail.com
}

Keywords

Bioenergy;

Biofuels;

Lignocellulosic

Residues; MFC.

\begin{abstract}
Bioenergy is the renewable and sustainable source of energy produced from organic matter. The matter used to produce such energy is called as biomass or the biological material used as a biofuel. The challenge of depleting non-renewable resources can be addressed by exploiting the capability of biotic systems to produce bioenergy. Species of every kingdom has a potential to be used as source of bioenergy. The study talks about switching from first generation biofuels produced from sugars and seed oils to fourth generation biofuels which involves metabolically engineered plants. Recent developments in molecular biology techniques that have provided valuable tool which could help to optimize and control the process in an effective way in the future have been discussed. The paper presents the production of biofuels from fungi acting upon lignocellulosic materials. Lignocellulosic residues from wood, grass, agricultural and municipal solid wastes are abundant in nature and have a potential for bioconversion. The synthesis of nanostructures using fungi can act as super capacitors and is helpful in storage of bioenergy. The paper also discusses the employment of bacteria in Microbial Fuel Cell (MFC). The capability of bacteria to produce electricity acting upon lots of carbohydrates present in industrial waste water and thereby treating it, is the working principle of these microbial fuel cells. General biochemistry involved has also been presented. However there are limitations with every means and some new approach has to be established to match the demand. (C) 2016 iGlobal Research and Publishing Foundation. All rights reserved.
\end{abstract}

Conference Proceedings: International Conference on Advances in Plant and Microbial Biotechnology (PMB-2017); JIIT, Noida: February 02-04, 2017

Indo Global Journal of Pharmaceutical Sciences( ISSN 22491023 ; CODEN- IGJPAI; NLM ID: 101610675) indexed and abstracted in EMBASE(Elsevier), SCIRUS(Elsevier),CABI, CAB Abstracts, Chemical Abstract Services(CAS), American Chemical Society(ACS), Index Copernicus, EBSCO, DOAJ, Google Scholar and many more. For further details, visit http://iglobaljournal.com 